\title{
Predictors of early treatment discontinuation in patients enrolled on Phase I oncology trials
}

\author{
David M. Hyman ${ }^{1,4, *}$, Anne A. Eaton ${ }^{2, *}{ }^{*}$ Mrinal M. Gounder ${ }^{1,4}$, Erika G. Pamer ${ }^{1}$, \\ Jasmine Pettiford ${ }^{1}$, Richard D. Carvajal ${ }^{1,4}$, S. Percy Ivy ${ }^{3}$, Alexia Iasonos ${ }^{2,4}$, David \\ R. Spriggs ${ }^{1,4}$

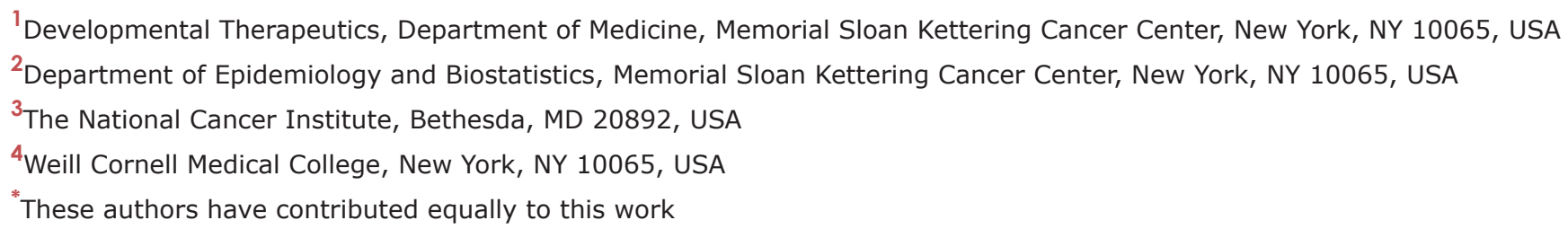

Correspondence to:

David M. Hyman, e-mail: hymand@mskcc.org

Keywords: Phase I trials, Early Discontinuation, Drug Development

Received: October 21, $2014 \quad$ Accepted: December 11,2014 Published: February 17, 2015

\section{ABSTRACT}

Purpose

Patients who do not complete one cycle of therapy on Phase I trials for reasons other than dose limiting toxicity (DLT) are considered inevaluable for toxicity and must be replaced.

Methods

Individual records from patients enrolled to NCI-sponsored Phase I trials activated between 2000 and 2010 were used. Early discontinuation was defined as the failure to begin cycle 2 for reasons other than a DLT during cycle 1. A multinomial logistic regression with a 3-level nominal outcome (early discontinuation, DLT during cycle 1, and continuation to cycle 2 ) was used with continuation to cycle 2 serving as the reference category. The final model was used to create two risk scores. An independent external cohort was used to validate these models.

Results

Data from 3079 patients on 127 Phase I trials were analyzed. ECOG performance status $(1, \geq 2$, two-sided $P=.0315$ and $P=.0007)$, creatinine clearance $(<60 \mathrm{ml} /$ min, $P=.0455)$, alkaline phosphatase $(>2.5 x$ ULN, $P=.0026)$, AST $(>$ ULN, $P=.0076)$, hemoglobin ( $<10 \mathrm{~g} / \mathrm{dL}, P<.0001)$, albumin $(<3.5 \mathrm{~g} / \mathrm{dL}, P<.0001)$, and platelets $(<400 \times 109 / L, P=.0732)$ were predictors of early discontinuation. The $c$-index of the final model was 0.63 .

Conclusion

Knowledge of risk factors for early treatment discontinuation in conjunction with clinical judgment can help guide Phase I patient selection. 


\section{INTRODUCTION}

Phase I eligibility criteria are intended to select fit patients with good performance status, near normal organ function, and minimal co-morbidities in order to accurately characterize the toxicity of the investigational drug [1-5]. In addition, patients with poor performance status or compromised organ function may be at increased risk for exacerbation of cancer symptoms, rapid disease progression, and death, thus necessitating discontinuation of protocol treatment during the first cycle [6-11]. Patient satisfaction with the Phase I experience may be adversely impacted by early discontinuation and their participation may delay implementation of more appropriate palliative care services [12-14]. Morever, patients who do not complete at least one cycle of therapy on Phase I trials for reasons other than dose limiting toxicity (DLT) are typically considered inevaluable for toxicity and must therefore be replaced [15]. Early discontinuation leads to delays in dose escalation as cohorts are backfilled and adds additional costs to the conduct of these studies.

Unfortunately, early trial discontinuation remains a fairly common event in Phase I studies despite strict entry criteria. In one large series, $16 \%$ of patients enrolled to Phase I trials discontinued protocol therapy within the first 21 days of beginning treatment [7]. Although prognostic risk scores are available to estimate the 90day overall survival of Phase I trial participants, little is known about what factors put patients at risk for early trial discontinuation. No risk score or predictive model is available to estimate the risk of early discontinuation among Phase I eligible patients. In order to address this unmet need, we analyzed the individual patient records from a large cohort of 3079 patients enrolled to 127 National Cancer Institute (NCI)-sponsored Phase I clinical trials from 67 institutions throughout North America with the aim of identifying risk factors and developing a risk score for early discontinuation.

\section{METHODS}

\section{Study design and patient eligibility}

A multicenter cohort of all patients treated on NCIsponsored [16] Phase I trials activated between 2000 and 2010 who met the following inclusion and exclusion criteria was used for model and risk score derivation. Data were provided from the Clinical Trials Monitoring System (CTMS) database, which is managed by Theradex Systems, Inc. The CTMS database is prospectively maintained with robust data management and auditing practices [17]. Trials of vaccines, immunotherapy, radiation therapy, loco-regional therapies, and autologous or allogeneic stem cell transplant were excluded. Organ dysfunction studies were also excluded. Eligible patients were adults ( $\geq 18$ years) with solid tumors excluding lymphoma. Patients were required to meet a common set of Phase I laboratory criteria as follows: absolute neutrophil count (ANC) $\geq 1 \times 10^{9} / \mathrm{L}$, hemoglobin $\geq 8 \mathrm{~g} /$ $\mathrm{dL}$, platelet count $\geq 75 \times 10^{9} / \mathrm{L}$, aspartate aminotransferase (AST) or alanine aminotransferase (ALT) $\leq 5 \mathrm{x}$ upper limit of normal (ULN), and total bilirubin $\leq 2 x$ ULN. This led to the exclusion of $5 \%$ of patients in the derivation dataset, reducing the number of patients from 3910 to 3717. Patients with incomplete data for one or more of the covariates included in the final multivariate model were also excluded. On this basis, $17 \%(N=638)$ of the 3717 patients in the derivation set were excluded. Baseline characteristics of patients with complete and missing data were largely similar (data not shown). All patients had regular follow-up visits as specified by the protocol to which they were enrolled. Patients must have received at least one dose of study drug(s) to be included in the analysis.

An independent cohort of 232 patients consecutively enrolled to 20 Phase I trials between 2009 and 2012 in the Developmental Therapeutics Clinic at Memorial Sloan Kettering Cancer Center was used as a validation set. CTEP-sponsored studies included in the derivation set were excluded from this cohort. Patients and trials in the validation set were required to meet the same eligibility criteria as the derivation set.

\section{Outcome}

The primary outcome for each patient was early discontinuation (yes/no), which was defined as: 1) the inability to begin cycle 2 of therapy, and 2) the absence of any dose limiting toxicity (DLT) during cycle 1 . The DLT criteria were standardized to allow for a uniform outcome definition across all trials and were defined as a grade $\geq 3$ non-hematologic or grade $\geq 4$ hematologic toxicity attributed as at least possibly related to study treatment, excluding asymptomatic electrolyte abnormalities. Toxicity level data were used to determine whether each patient had an adverse event that qualified under this definition of DLT. These DLT criteria are commonly used in contemporary Phase I studies $[15,18]$.

\section{Candidate factors}

The following categories of baseline patient characteristics were investigated for their association with early trial discontinuation: 1) commonly utilized Phase I eligibility criteria, 2) established prognostic factors, 3) prior treatment exposure, and 4) disease burden.

\section{Model and risk score building and validation}

All variables except ECOG performance status (PS) were dichotomized to facilitate the final goal of creating a simple risk score. Cutoffs were chosen based on upper limit of normal and/or cutoffs defined by the NCI Common 
Terminology Criteria of Adverse Events (CTCAE), most commonly using the criteria for grade 1 abnormalities. For certain covariates, grade 1 abnormalities were very common and would therefore have been of limited discriminatory utility and in those cases criteria for grade 2 abnormalities were utilized. Similarly, cutoffs that would identify a small minority of patients and thus have limited clinical utility and statistical properties were avoided. ECOG PS was treated as a categorical variable with three levels: 0,1 , and $\geq 2$. Due to concern about the heterogeneity of the patients who did not discontinue early (this group contains both patients who experienced a DLT during cycle 1 and patients who began cycle 2 without a DLT), multinomial logistic regression with a 3-level nominal outcome (early discontinuation as defined above, DLT during cycle 1, and continuation to cycle 2) was used to assess relationships between factors and outcome. Continuation to cycle 2 was the reference category.

Candidate factors for the multivariate model were selected based on clinical reasoning and univariate results, and the final model was selected using a backward selection procedure where variables with the largest discontinuation-specific $P$-value (ie, the $P$-value associated with the odds ratio for early discontinuation versus continuation to cycle 2) were sequentially removed until all discontinuation-specific $P$-values were $<0.10$. The final logistic model assigns each patient a predicted risk of cycle 1 DLT, early discontinuation, and continuation to cycle 2 . The binary outcome for model validation was early discontinuation (yes/no), with cycle 1 DLT and continuation to cycle 2 combined. Predictive accuracy of the multinomial logistic model was evaluated with the concordance-index (c-index), which estimates the proportion of pairs where the patient who discontinued early has a higher model-predicted risk of early discontinuation than the patient who did not discontinue early.

The final multinomial model (based on Hosmer equations 8.1 to 8.5 [19]) was used to create two risk scores. In the expanded risk score, points were assigned to each risk factor in order to best preserve the ranking of the patients' risk of early discontinuation assigned by the full model, while ensuring that the model was not overly complex [20]. A simplified risk score was subsequently developed in which only the strongest factors (those assigned 2 points in the expanded risk score) contribute one point each. Ninety-five percent confidence intervals for sensitivity, specificity, and overall correct classification rate were calculated using exact confidence intervals for binomial proportions.

The risk scores were dichotomized at various cutoff points to define patients at low and high risk of early discontinuation. Overall correct classification rate was defined as the percent of patients who were classified correctly: either as low risk and did not discontinue early, or as high risk and did discontinue early. Two cutoffs
( 5 for the expanded risk score, and 2 for the simplified risk score) were selected based on their performance in the CTEP data, with an emphasis on high specificity, which translates to a low probability of classifying patients who did not discontinue early as high risk. These were then validated on an external dataset. C-index, sensitivity, specificity, and overall correct classification rate were used to assess full model performance and risk score performance in the external data.

All statistical analysis was performed in SAS 9.2 (SAS Institute, Cary, NC) and R 3.0.1 (R Foundation, Vienna, Austria) using the pROC and verification packages. All $P$-values were two-sided, and $P$-values less than 0.05 were considered significant.

\section{RESULTS}

\section{Patient characteristics, derivation set}

Data on 3079 patients treated on 127 Phase I trials were analyzed. Baseline patient characteristics are presented in Table 1. A broad range of tumor types was represented. The median number of prior systemic therapies was 3 (range, 0-19). Median values of pretreatment hemoglobin, platelets, calculated creatinine clearance, AST, and ALT were all within the range of normal (data not shown). In total, 508 (16.5\%) patients met criteria for early discontinuation. Sixty-one percent $(N=312)$ discontinued early for clinical progression or death, $23 \%(N=115)$ for an adverse event that was not a DLT, and $2 \%(N=10)$ for other reasons. No off study reason was provided for $14 \%(N=71)$ of the patients who discontinued early.

\section{Model building and validation}

The association of baseline patient characteristics to the likelihood of early trial discontinuation was examined in the derivation set by both univariate and multivariate analysis. The results of these analyses are presented in Table 2. On univariate analysis, higher ECOG PS ( $P=0.0008$ and $P<.0001$ for PS $1, \geq 2$ respectively), WBC $(P=0.0005)$, platelet count $(P<.0001)$, AST $(P<$ $.0001)$, alkaline phosphatase $(P<.0001)$, ALT $(P=0.0305)$, number of prior lines of therapy $(P=0.0554, P=0.0063$ for $3, \geq 4$ respectively) and lower hemoglobin $(P<.0001)$, creatinine clearance $(P=0.0289)$, number of metastatic sites $(P=0.0753, P=0.0421$ and $P=0.0076$ for 1,2 and $\geq$ 3 respectively), and albumin $(P<.0001)$ were significantly associated with the risk of early discontinuation. Primary tumor site was not considered a candidate for the multivariate model because we did not wish to discriminate against specific tumor types. Similarly, prior lines of therapy and number of metastatic sites were not candidates for the final model because we did not wish to exclude broad groups of patients who constitute a significant proportion 
Table 1: Patient characteristics, derivation set $(N=3079)$

\begin{tabular}{|c|c|c|}
\hline Characteristic & No. & $\%$ \\
\hline Age & 58 (median) & $18-87$ (range) \\
\hline \multicolumn{3}{|l|}{ Sex } \\
\hline Male & 1528 & $50 \%$ \\
\hline Female & 1551 & $50 \%$ \\
\hline \multicolumn{3}{|l|}{ Primary Tumor Site } \\
\hline Gastrointestinal & 1060 & $34 \%$ \\
\hline Genitourinary & 371 & $12 \%$ \\
\hline Thoracic & 366 & $12 \%$ \\
\hline Breast & 349 & $11 \%$ \\
\hline Gynecologic & 291 & $9 \%$ \\
\hline Sarcoma & 242 & $8 \%$ \\
\hline Head and Neck & 197 & $6 \%$ \\
\hline Melanoma and Skin & 162 & $5 \%$ \\
\hline Brain and Unknown & 41 & $1 \%$ \\
\hline \multicolumn{3}{|c|}{ ECOG performance status } \\
\hline 0 & 885 & $29 \%$ \\
\hline 1 & 2040 & $66 \%$ \\
\hline$\geq 2$ & 154 & $5 \%$ \\
\hline \multicolumn{3}{|c|}{ Number of Prior Systemic Therapies" } \\
\hline $0-2$ & 1374 & $45 \%$ \\
\hline 3 & 555 & $18 \%$ \\
\hline$\geq 4$ & 1150 & $37 \%$ \\
\hline \multicolumn{3}{|l|}{ Prior Radiation* } \\
\hline Yes & 1433 & $47 \%$ \\
\hline No & 1641 & $53 \%$ \\
\hline \multicolumn{3}{|c|}{ Number of Metastatic Sites" } \\
\hline 0 & 145 & $5 \%$ \\
\hline 1 & 525 & $18 \%$ \\
\hline 2 & 590 & $21 \%$ \\
\hline$>2$ & 1588 & $56 \%$ \\
\hline \multicolumn{3}{|c|}{ Metastatic Sites (231 missing) ${ }^{{ }^{* 1}}$} \\
\hline Lung & 1101 & $39 \%$ \\
\hline Liver & 1081 & $38 \%$ \\
\hline Lymph Node & 609 & $21 \%$ \\
\hline Bone & 216 & $8 \%$ \\
\hline Brain & 8 & $0 \%$ \\
\hline
\end{tabular}

(Continued) 


\begin{tabular}{|c|c|c|}
\hline Characteristic & No. & $\%$ \\
\hline $\begin{array}{l}\text { Sum, Longest Tumor Dimensions (cm) } \\
\text { (271 missing) }\end{array}$ & 8.1 (median) & $0-49.5$ (range) \\
\hline \multicolumn{3}{|l|}{ BMI $\left(\mathrm{kg} / \mathrm{m}^{2}\right)^{*}$} \\
\hline$<18.5$ & 101 & $3 \%$ \\
\hline$\geq 18.5$ & 2961 & $97 \%$ \\
\hline \multicolumn{3}{|l|}{ Laboratories } \\
\hline WBC $\left(10^{9} / \mathrm{L}\right) \geq 10.5(2 \text { missing })^{*}$ & 329 & $11 \%$ \\
\hline $\operatorname{ALC}\left(10^{9} / \mathrm{L}\right)<0.5(77 \text { missing })^{*}$ & 187 & $6 \%$ \\
\hline Hemoglobin $(\mathrm{g} / \mathrm{dL})<10$ & 273 & $9 \%$ \\
\hline Platelets $\left(10^{9} / \mathrm{L}\right) \geq 400$ & 405 & $13 \%$ \\
\hline Platelets $\left(10^{9} / \mathrm{L}\right)<150$ & 230 & $7 \%$ \\
\hline Albumin $(\mathrm{g} / \mathrm{dL})<3.5$ & 802 & $26 \%$ \\
\hline AST (units/L) $>$ ULN & 788 & $26 \%$ \\
\hline ALT (units/L) > ULN (92 missing)* & 588 & $17 \%$ \\
\hline Total bilirubin $(\mathrm{mg} / \mathrm{dL})>1$ ( 8 missing $)^{*}$ & 151 & $5 \%$ \\
\hline Alkaline Phosphatase (units/L) $>2.5 x U L N$ & 355 & $12 \%$ \\
\hline Creatinine clearance $(\mathrm{mL} / \mathrm{min})^{2}<60$ & 380 & $12 \%$ \\
\hline \multicolumn{3}{|l|}{ Pain at Baseline } \\
\hline Yes & 208 & $7 \%$ \\
\hline No & 2871 & $93 \%$ \\
\hline
\end{tabular}

1- Patients may fall into more than one category for these covariates.

2- Estimated by Cockcroft-Gault equation, capped at $125 \mathrm{~mL} / \mathrm{min}$.

* Some patients were missing this covariate and were excluded.

of the Phase I eligible population from participation in these studies. Other significant variables were carried forward to a multivariate model, where WBC, ALT, and absolute lymphocyte count (ALC) were not independent predictors of early discontinuation $(P>0.10)$ and were subsequently removed from the model, yielding the final model. The final multivariate model, accounting for ECOG PS $(1, \geq 2$, $P=0.0315$ and $P=0.0007$ respectively), creatinine clearance $(<60 \mathrm{ml} / \mathrm{min}, P=0.0455)$, alkaline phosphatase $(>2.5 \mathrm{xULN}, P=0.0026)$, AST ( $>\mathrm{ULN}, P=0.0076)$, hemoglobin $(<10 \mathrm{~g} / \mathrm{dL}, P<.0001)$, albumin $(<3.5 \mathrm{~g} / \mathrm{dL}$, $P<.0001)$, and platelet count $\left(<400 \times 10^{9} / \mathrm{L}, P=0.0732\right)$ had a c-index of 0.63 in the derivation set. The c-index of this model with all the covariates included as continuous except ECOG PS was 0.64, and the c-index of our final model with the additional covariates number of prior lines of treatment and number of metastatic sites is 0.64 ; thus we feel that our modeling choices did not lead to decreased model performance. The odds ratios for both outcomes of the final multinomial model are shown in Supplemental Table 1A. The performance of the final multivariate model was also assessed in an independent external validation set $(N=232)$. The rate of early discontinuation in the validation set was $15 \%$. The derivation and validation sets were well balanced with regards to the presence of factors independently associated with the risk of early discontinuation (see Supplemental Table 2A). The cumulative distribution of predicted risk of early discontinuation in the derivation and external validation sets was also similar, as demonstrated in Figure 1. The c-index of the final model in the external validation set was 0.61 .

\section{Risk score performance}

In order to create a user-friendly clinical decision aid, two risk scores were developed utilizing the final multivariate model and assessed for performance. The two proposed risks scores and their associated sensitivity, specificity, and overall correct classification rate (OCCR) in both the derivation and validation sets are shown in Table 3. An expanded risk score assigns 2 points each for: ECOG PS $(\geq 2)$, alkaline phosphatase ( $>2.5 \times \mathrm{xULN})$, hemoglobin $(<10 \mathrm{~g} / \mathrm{dL})$, and albumin $(<3.5 \mathrm{~g} / \mathrm{dL})$, and 1 point each for: ECOG PS $(=1)$, creatinine clearance 
Table 2: Univariate and multivariate analysis, derivation set

\begin{tabular}{|c|c|c|c|c|}
\hline Factor & $\begin{array}{c}\text { Univariate } \text { OR }^{1}(95 \% \\
\text { CI })\end{array}$ & $P$ value & $\begin{array}{l}\text { Multivariate OR } \\
\qquad(95 \% \mathrm{CI})\end{array}$ & $P$ value \\
\hline \multicolumn{5}{|l|}{ ECOG } \\
\hline 0 & Ref & - & Ref & - \\
\hline 1 & $1.49(1.18-1.88)$ & 0.0008 & $1.30(1.02-1.65)$ & 0.0315 \\
\hline$\geq 2$ & $3.23(2.07-5.03)$ & $<.0001$ & $2.22(1.40-3.53)$ & 0.0007 \\
\hline \multicolumn{5}{|c|}{ Albumin (g/dL) } \\
\hline$<3.5$ & $2.22(1.79-2.74)$ & $<.0001$ & $1.59(1.26-2.00)$ & $<.0001$ \\
\hline$\geq 3.5$ & Ref & - & Ref & - \\
\hline \multicolumn{5}{|c|}{$\begin{array}{l}\text { Alkaline Phosphatase } \\
\text { (units/L) }\end{array}$} \\
\hline$\leq 2.5 \times U L N$ & Ref & - & Ref & - \\
\hline$>2.5 \times U L N$ & $2.43(1.84-3.20)$ & $<.0001$ & $1.62(1.18-2.22)$ & 0.0026 \\
\hline \multicolumn{5}{|l|}{ AST (units/L) } \\
\hline$\leq \mathrm{ULN}$ & Ref & - & Ref & - \\
\hline$>\mathrm{ULN}$ & $1.69(1.36-2.10)$ & $<.0001$ & $1.39(1.09-1.77)$ & 0.0076 \\
\hline \multicolumn{5}{|c|}{$\begin{array}{l}\text { Creatinine clearance } \\
(\mathrm{mL} / \mathrm{min})\end{array}$} \\
\hline$<60$ & $1.38(1.03-1.83)$ & 0.0289 & $1.35(1.01-1.81)$ & 0.0455 \\
\hline$\geq 60$ & Ref & - & Ref & - \\
\hline \multicolumn{5}{|c|}{ Hemoglobin (g/dL) } \\
\hline$<10$ & $2.79(2.09-3.72)$ & $<.0001$ & $1.99(1.46-2.71)$ & $<.0001$ \\
\hline$\geq 10$ & Ref & - & Ref & - \\
\hline \multicolumn{5}{|c|}{ Platelets $\left(10^{9} / \mathrm{L}\right)$} \\
\hline$<400$ & Ref & - & Ref & - \\
\hline$\geq 400$ & $1.80(1.39-2.35)$ & $<.0001$ & $1.30(0.98-1.72)$ & 0.0732 \\
\hline \multicolumn{5}{|c|}{ Platelets $\left(10^{9} / \mathrm{L}\right)$} \\
\hline$<150$ & $1.26(0.87-1.81)$ & 0.2790 & NA & NA \\
\hline$\geq 150$ & Ref & - & & \\
\hline \multicolumn{5}{|l|}{ ALT (units/L) } \\
\hline$\leq \mathrm{ULN}$ & Ref & - & NA & NA \\
\hline$>\mathrm{ULN}$ & $1.31(1.03-1.67)$ & 0.0305 & & \\
\hline \multicolumn{5}{|l|}{ WBC $\left(10^{9} / \mathrm{L}\right)$} \\
\hline$<4$ & $1.27(0.82-1.97)$ & 0.2790 & NA & NA \\
\hline$\geq 4$ & Ref & & & \\
\hline \multicolumn{5}{|l|}{ WBC $\left(10^{9} / \mathrm{L}\right)$} \\
\hline$<10.5$ & Ref & - & NA & NA \\
\hline$\geq 10.5$ & $1.68(1.25-2.25)$ & 0.0005 & & \\
\hline $\operatorname{ALC}\left(10^{9} / \mathrm{L}\right)$ & & & & \\
\hline
\end{tabular}

(Continued) 


\begin{tabular}{|c|c|c|c|c|}
\hline Factor & $\begin{array}{c}\text { Univariate } \mathrm{OR}^{1}(95 \% \\
\mathrm{CI})\end{array}$ & $P$ value & $\begin{array}{c}\text { Multivariate OR } \\
(95 \% \mathrm{CI})\end{array}$ & $P$ value \\
\hline$<0.5$ & $1.47(0.99-2.16)$ & 0.0538 & NA & NA \\
\hline$\geq 0.5$ & Ref & - & & \\
\hline \multicolumn{5}{|l|}{$\begin{array}{l}\text { Number of Metastatic } \\
\text { Sites }\end{array}$} \\
\hline 0 & Ref & - & NA & NA \\
\hline 1 & $0.66(0.41-1.04)$ & 0.0753 & & \\
\hline 2 & $0.62(0.40-0.98)$ & 0.0421 & & \\
\hline$\geq 3$ & $0.56(0.37-0.86)$ & 0.0076 & & \\
\hline \multicolumn{5}{|l|}{$\begin{array}{l}\text { Sum. Longest Tumor } \\
\text { Dimensions }(\mathrm{cm})\end{array}$} \\
\hline$\leq 8$ & Ref & - & NA & NA \\
\hline$>8$ & $1.06(0.86-1.30)$ & 0.6121 & & \\
\hline \multicolumn{5}{|l|}{ BMI $\left(\mathrm{kg} / \mathrm{m}^{2}\right)$} \\
\hline$<18.5$ & $1.59(0.98-2.60)$ & - & NA & NA \\
\hline$\geq 18.5$ & Ref & 0.0616 & & \\
\hline \multicolumn{5}{|l|}{ Primary Site } \\
\hline Brain & $1.04(0.21-5.17)$ & 0.9669 & NA & NA \\
\hline Breast & $1.07(0.78-1.49)$ & 0.7541 & & \\
\hline Gastrointestinal & Ref & - & & \\
\hline Genitourinary & $0.58(0.40-0.83)$ & 0.0028 & & \\
\hline Gynecologic & $0.65(0.45-0.95)$ & 0.0266 & & \\
\hline Head and neck & $0.68(0.43-1.06)$ & 0.0847 & & \\
\hline Melanoma and skin & $0.74(0.46-1.19)$ & 0.2120 & & \\
\hline Sarcoma & $0.68(0.46-1.01)$ & 0.0563 & & \\
\hline Thoracic & $0.99(0.72-1.37)$ & 0.9729 & & \\
\hline Unknown & $0.83(0.27-2.52)$ & 0.7395 & & \\
\hline \multicolumn{5}{|l|}{ Pain at Baseline } \\
\hline No & Ref & - & NA & NA \\
\hline Yes & $0.72(0.47-1.10)$ & 0.1287 & & \\
\hline \multicolumn{5}{|l|}{\begin{tabular}{|l} 
Prior Lines of \\
Systemic Therapy
\end{tabular}} \\
\hline $0-2$ & Ref & - & NA & NA \\
\hline 3 & $1.31(0.99-1.42)$ & 0.0554 & & \\
\hline$\geq 4$ & $1.36(1.09-1.69)$ & 0.0063 & & \\
\hline
\end{tabular}

1- Odd-ratios are for early discontinuation with continuation to cycle 2 as the reference category.

$(<60 \mathrm{ml} / \mathrm{min})$, AST $(>\mathrm{ULN})$, and platelets $\left(>400 \times 10^{9} / \mathrm{L}\right)$. A simplified risk score further condenses the multivariate model by assigning 1 point each for the four characteristics with the largest impact on the risk of early discontinuation:
ECOG PS $(\geq 2)$, albumin $(<3.5 \mathrm{~g} / \mathrm{dL})$, alkaline phosphatase $(>2.5 \mathrm{xULN})$, and hemoglobin $(<10 \mathrm{~g} / \mathrm{dL})$.

Figure 2 demonstrates the relationship of increasing points for the expanded and simplified risk scores to the 


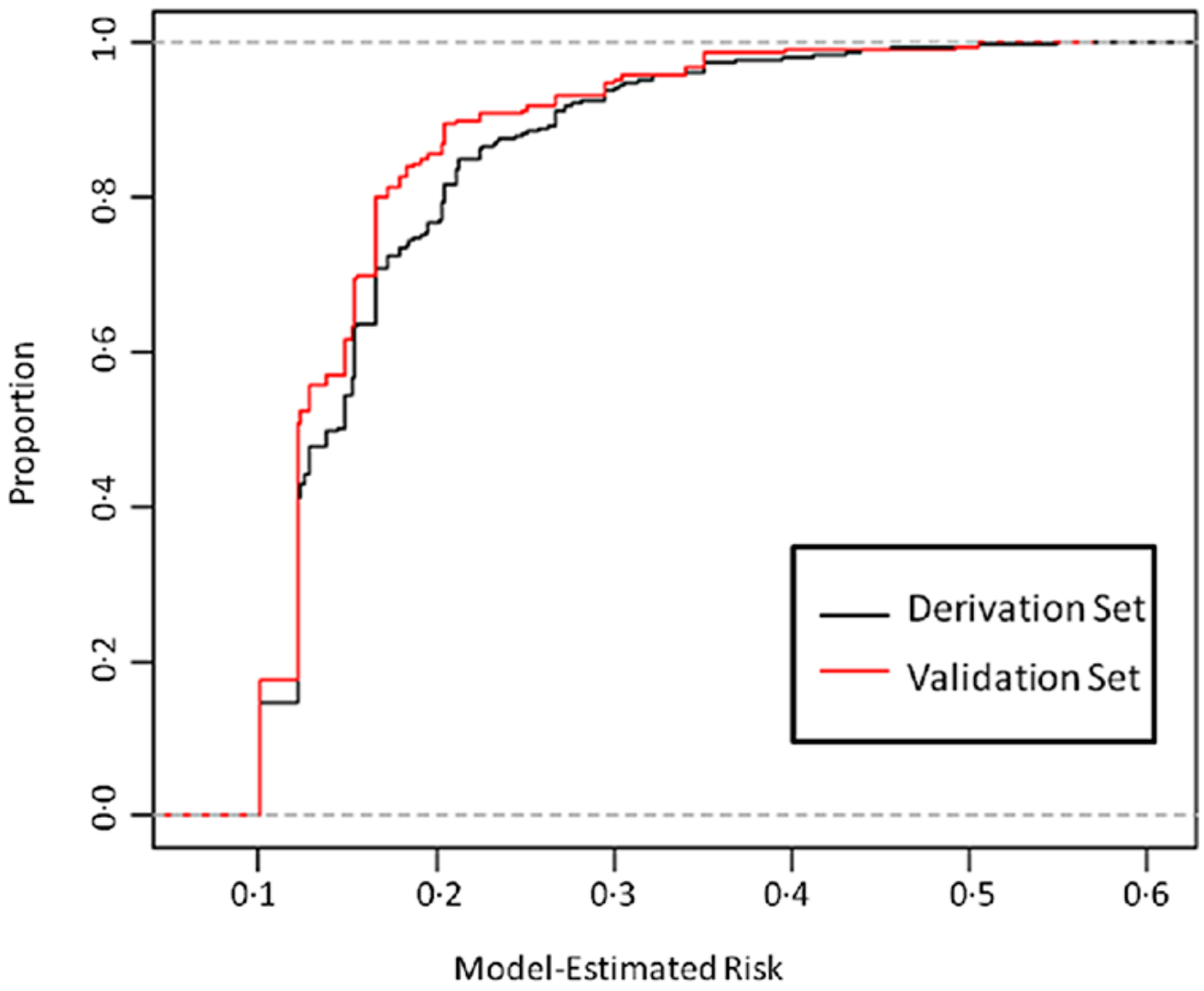

Figure 1: Cumulative distribution of multivariate model-estimated risk, derivation and validation set. The black line represents the proportion of patients in the derivation set with an estimated risk at or below a given risk (x-axis). The red line represents the proportion of patients in the validation set with an estimated risk at or below a given risk (x-axis).

a)

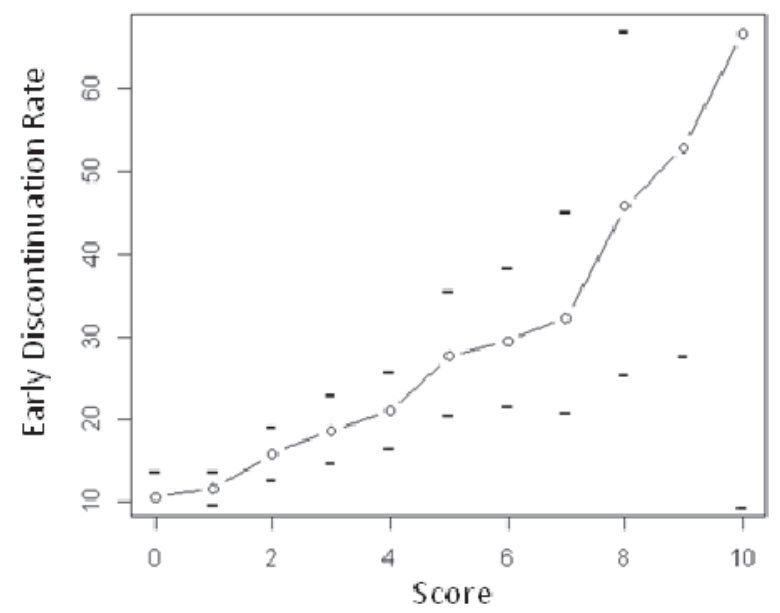

\begin{tabular}{|l|l|l|l|l|l|l|}
\hline Points & 0 & 2 & 4 & 6 & 8 & 10 \\
\hline Observed Rate & $11 \%$ & $16 \%$ & $21 \%$ & $30 \%$ & $46 \%$ & $67 \%$ \\
\hline
\end{tabular}

b

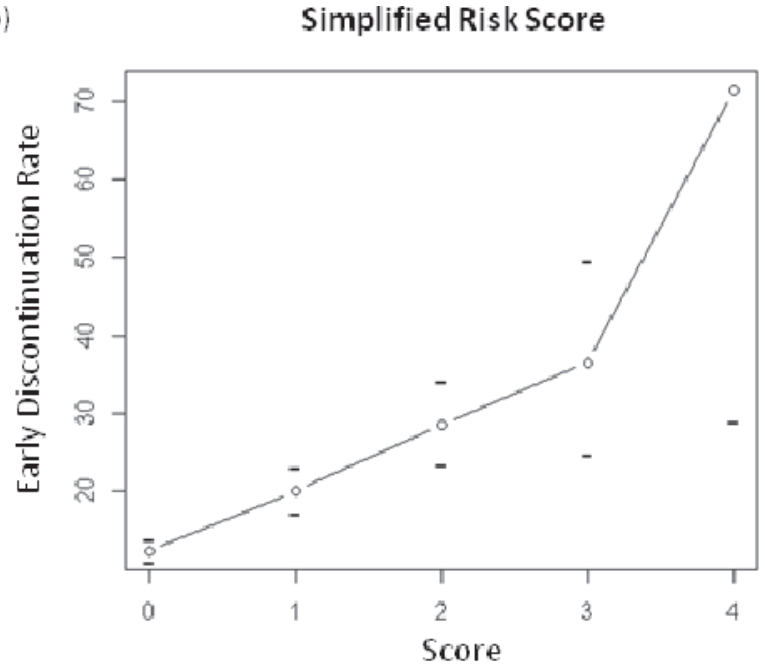

\begin{tabular}{|l|l|l|l|l|l|}
\hline Points & 0 & $\mathbf{1}$ & 2 & 3 & $\mathbf{4}$ \\
\hline Observed Rate & $12 \%$ & $20 \%$ & $29 \%$ & $37 \%$ & $71 \%$ \\
\hline
\end{tabular}

Figure 2: Relationship between model predicted score and observed early discontinuation rate, derivation set. The line represents the total score [(A) expanded risk score, (B) simplified risk score] (x-axis) matched to the observed probability of early discontinuation (y-axis). Horizontal tick marks represents the $95 \%$ confidence interval around each estimate. The tables show the observed early discontinuation rate for selected scores. 
observed early discontinuation rate in the derivation set. The performance of proposed cutoffs for both risk scores are presented in Table 3 . In the derivation set, patients with $\geq 5$ points on the expanded risk score or $\geq 2$ points on the simplified risk score had approximately twice the observed rate of early discontinuation compared to patients with lower scores (31.6\% vs $14.4 \%$ and $30.8 \%$ vs $14.6 \%$, respectively, Figure 3 ). Patients with $\geq 3$ points on the simplified risk score had a $40 \%$ likelihood of early discontinuation. Using these same point cutoffs ( 5 and 2 for the expanded and simplified risk scores, respectively), the overall correct classification rates (OCCRs) for both

Table 3: Diagnostic accuracy of risk scores, derivation and validation sets

Expanded Risk Score $^{1}$
$\frac{2 \text { Points Each }}{\text { - ECOG 2, Alkaline Phosphatase } \geq 2.5 x U L N, \text { Hemoglobin } \leq 10, \text { and Albumin } \leq 3.5}$
1Point Each - ECOG 1, Creatinine Clearance $\leq 60$, AST $\geq$ ULN, Platelets $\geq 400$

$\underline{\text { Simplified Risk Score }}^{2}$

1 Point Each: ECOG 2, Alkaline Phosphatase $\geq 2.5 x U L N$, Hemoglobin $\leq 10$, and Albumin $\leq 3.5$

\begin{tabular}{|l|c|c|c|}
\hline & & Derivation Set & Validation Set \\
\hline \multirow{3}{*}{$\begin{array}{l}\text { Expanded Risk Score: } \\
<5 \text { points vs } \geq 5 \text { points }\end{array}$} & Sensitivity $(95 \%$ CI) & $119 / 508=23.4 \%(19.8-27.4)$ & $3 / 34=8.8 \%(1.9-23.7)$ \\
\cline { 2 - 4 } & Specificity $(95 \%$ CI) & $2314 / 2571=90 \%(88.8-91.1)$ & $182 / 198=92 \%(87.2-95.3)$ \\
\cline { 2 - 4 } & OCCR $(95 \%$ CI) & $79 \%(77.5-80.5)$ & $79.7 \%(74.0-84.7)$ \\
\hline \multirow{3}{*}{$\begin{array}{l}\text { Simplified Risk Score: } \\
<2 \text { points vs } \geq 2 \text { points }\end{array}$} & Sensitivity $(95 \%$ CI) & $113 / 508=22.2 \%(18.7-26.1)$ & $4 / 34=11.8 \%(3.3-27.5)$ \\
\cline { 2 - 4 } & Specificity $(95 \%$ CI) & $2317 / 2571=90.1 \%(88.9-91.3)$ & $182 / 198=91.9 \%(87.2-95.3)$ \\
\cline { 2 - 4 } & OCCR $(95 \%$ CI) & $78.9 \%(77.4-80.4)$ & $80.2 \%(74.5-85.1)$ \\
\hline
\end{tabular}

1-Maximum possible score: 11

2- Maximum possible score: 4

OCCR: Overall Correct Classification Rate.

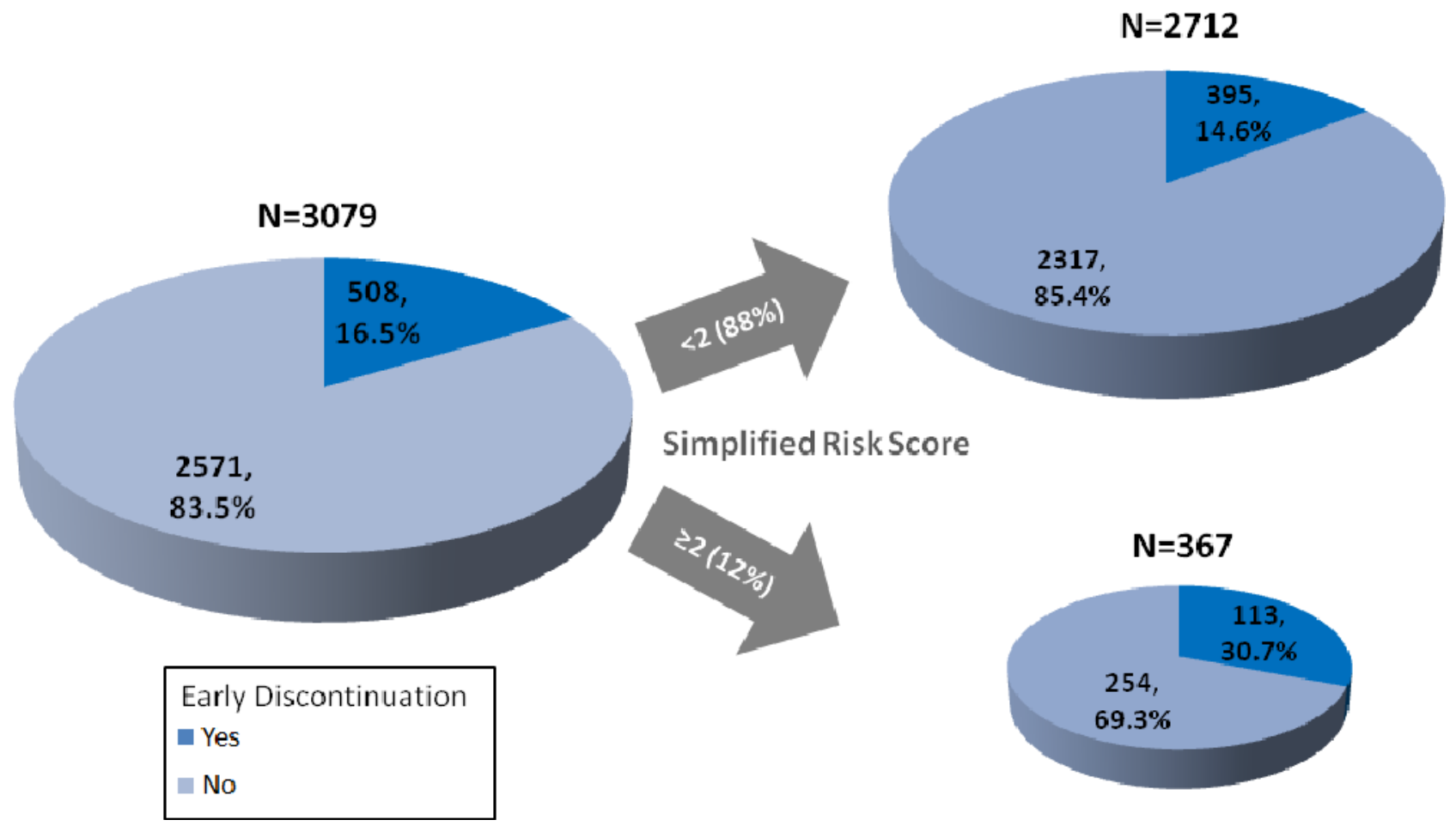

Figure 3: Impact of risk score on enrollment and early discontinuation. This figure demonstrates the impact on the derivation set of excluding patients with a simplified risk score $\geq 2$. 
risk scores were approximately $80 \%$ in both the derivation and validation sets. The performance of the risk scores in the subset of patients who received molecular targeted agents only is shown in Supplemental Table 3A.

\section{DISCUSSION}

Utilizing individual patient records from a very large, multi-institutional, contemporary cohort of North American patients enrolled to Phase I trials, we identified baseline clinical characteristics independently associated with the risk of early trial discontinuation. To our knowledge, this is the first such analysis performed to date. We identified several factors independently associated with early trial discontinuation including higher ECOG PS, alkaline phosphatase, AST, and platelets and decreasing albumin, hemoglobin, and creatinine clearance. These results offer important insights to physicians charged with selecting appropriate patients for Phase I trials.

Many of the risk factors identified here have previously been shown to be prognostic in the Phase I patient population [21]. Among patients who discontinue treatment early for reasons other than DLT, 61\% did so for clinical disease progression or death and $23 \%$ due to adverse events (both disease and drug-related). These rates are very consistent with data reported by the European Drug Development Network [7] and suggest that our large multi-center derivation cohort accurately reflects the contemporary Phase I population. These data also suggest that the population of patients who discontinue treatment early tend to have a poor prognosis. The overlap of prognostic factors for 90-day survival and early discontinuation, however, is not complete. For example, although lymphopenia (ALC $\left.<0.5 \times 10^{9} / \mathrm{L}\right)$ is frequently cited as a prognostic factor, it did not predict for early discontinuation after adjusting for other covariates. Creatinine clearance, an independent predictor of early discontinuation, is not a well established prognostic factor. Moreover, the likelihood of early discontinuation due to progression or death was similar in our overall population and for patients with $\geq 2$ points on our simplified risk score (see Supplemental Table 4A). These data suggest that patients who discontinue treatment early are not always those with the poorest prognosis and that excluding patients with poor prognosis does not eliminate early treatment discontinuation.

Using insight provided from the multivariate analysis, we created and externally validated two risk scores to identify patients at significantly increased risk for early discontinuation prior to enrollment. To arrive at this simplified risk score, we chose the risk factors with the greatest effect on early discontinuation (ECOG PS $\geq 2$, albumin $\leq 3.5 \mathrm{mg} / \mathrm{dL}$, alkaline phosphatase $\geq 2.5 \mathrm{x}$ ULN, and hemoglobin $\leq 10 \mathrm{mg} / \mathrm{dL}$ ). Patients with $\geq 2$ of these risk factors prior to enrollment had an observed rate of early discontinuation of $31 \%$, approximately twice the rate of the overall population (16.5\%). By comparison, patients with none of these risk factors had only a $12 \%$ chance of discontinuing early, a relative risk reduction of $27 \%$ compared to the overall population. Both risk scores had similar performance in the derivation and validation sets, suggesting they are generalizable to new patient populations. Additionally, the risk scores performed similarly when assessed in the subset of patients who received molecular targeted agents only, indicating that these scores will continue to be relevant as drug development becomes more focused on these agents.

To illustrate how using the simplified risk score would impact patient selection and the composition of Phase I trials, Figure 3 shows the results of limiting accrual in the derivation cohort to patients with $<2$ points on the simplified risk score. Enrollment of $11.9 \%$ (367/3079) patients would be curtailed by applying a cutoff of $\geq 2$ points on the simplified risk score. The rate of early discontinuation in the remaining patients would be $14.6 \%$ (395/2712), compared to $16.5 \%$ (508/3079) in the original derivation set. In total, 113 fewer patients would discontinue early and 22.2\% (113/508) of all early discontinuations would be avoided at the expense of curtailing enrollment by 367 patients. This cutoff would improperly exclude only $10 \%$ of those who do not discontinue early at the expense of failing to identify $78 \%$ of the patients who do discontinue early. This cutoff was chosen to minimize the impact on the overall pool of Phase I eligible patients while still providing a decrease in the number of patients who discontinue early. However, it is important to note that this cutoff would also improperly exclude 7 patients for every 3 patients accurately excluded. This "false positive" rate represents an important obstacle to the use of these scores in routine clinical practice. Even if these risk scores were implemented, early discontinuation rates would remain $>$ $10 \%$. It is therefore important that Phase I study sponsors account for this potentially unavoidable feature of the Phase I patient population when designing and conducting these studies. Study designs that minimize the need for delays in patient enrollment and dose escalation when one or more patients are inevaluable for toxicity due to early treatment discontinuation offer potentially significant advantages in the conduct of these studies [23].

Unfortunately, the number of patients seeking Phase I trials often exceeds study availability at high volume centers. As such, physicians often must select from multiple potentially eligible patients for a limited number of study spots. In doing so, physicians attempt to identify which patients are most likely to remain on study long enough to potentially benefit. Currently, physicians must rely solely on clinical experience to make these difficult judgments. In these circumstances, we believe that even highly expert Phase I investigators can benefit from the knowledge of how a limited number of objective patient characteristics may increase the risk of early treatment discontinuation. 


\section{FUNDING SOURCE}

Funded in part by the Cancer Center core grant P30 CA008748. The core grant provides funding to institutional cores, such as Biostatistics, which was used in this study.

\section{Declaration of interests}

S. Percy Ivy, MD, is an employee of the National Cancer Institute.

\section{REFERENCES}

1. Ho J, Pond GR, Newman C, Chen EX, Oza AM, Siu LL. Barriers in Phase I cancer clinical trials referrals and enrollment: five-year experience at the Princess Margaret Hospital. BMC Cancer. 2006; 6:263.

2. Karavasilis V, Digue L, Arkenau T, Eaton D, Stapleton S, de Bono J, Judson I, Kaye S. Identification of factors limiting patient recruitment into Phase I trials: a study from the Royal Marsden Hospital. Eur J Cancer. 2008; 44:978-982.

3. Ivy SP, Siu LL, Garrett-Mayer E, Rubinstein L. Approaches to phase 1 clinical trial design focused on safety, efficiency, and selected patient populations: a report from the clinical trial design task force of the national cancer institute investigational drug steering committee. Clin Cancer Res. 2010; 16:1726-1736

4. Arimone Y, Begaud B, Miremont-Salame G, FourrierRéglat A, Moore N, Molimard M, Haramburu F. Agreement of expert judgment in causality assessment of adverse drug reactions. European J Clin Pharmacol. 2004; 61:169-173.

5. Mukherjee SD, Coombes ME, Levine M, Cosby J, Kowaleski B, Arnold A. A qualitative study evaluating causality attribution for serious adverse events during early phase oncology clinical trials. Investig New Drugs. 2011; 29:1013-1020.

6. Ploquin A, Olmos D, Lacombe D, A'Hern R, Duhamel A, Twelves C, Marsoni S, Morales-Barrera R, Soria JC, Verweij J, Voest EE, Schöffski P, Schellens JH, et al. Prediction of early death among patients enrolled in Phase I trials: development and validation of a new model based on platelet count and albumin. Br J Cancer. 2012; 107:1025-1030.

7. Olmos D, A'Hern RP, Marsoni S, Morales R, GomezRoca C, Verweij J, Voest EE, Schöffski P, Ang JE, Penel N, Schellens JH, Del Conte G, Brunetto AT, et al. Patient Selection for Oncology Phase I Trials: A MultiInstitutional Study of Prognostic Factors. J Clin Oncol. 2012; 30:996-1004.

8. Arkenau HT, Olmos D, Ang JE, de Bono J, Judson I, Kaye S. Clinical outcome and prognostic factors for patients treated within the context of a Phase I study: the Royal Marsden Hospital experience. Br J Cancer. 2008; 98:1029-1033.
9. Arkenau HT, Olmos D, Ang JE, Barriuso J, Karavasilis V, Ashley S, de Bono J, Judson I, Kaye S. 90-Days mortality rate in patients treated within the context of a phase-I trial: how should we identify patients who should not go on trial? Eur J Cancer. 2008; 44:1536-1540.

10. Arkenau HT, Barriuso J, Olmos D, Ang JE, de Bono J, Judson I, Kaye S. Prospective validation of a prognostic score to improve patient selection for oncology Phase I trials. J Clin Oncol. 2009; 27:2692-2696.

11. Brunetto AT, Ang JE, Olmos D, Tan D, Barriuso J, Arkenau HT, Yap TA, Molife LR, Banerji U, de Bono J, Judson I, Kaye S. A study of the pattern of hospital admissions in a specialist Phase I oncology trials unit: unplanned admissions as an early indicator of patient attrition. Eur J Cancer. 2010; 46:2739-2745.

12. Agrawal M, Grady C, Fairclough DL, Meropol NJ, Maynard K, Emanuel EJ. Patients' Decision-Making Process Regarding Participation in Phase I Oncology Research. J Clin Oncol. 2006; 24:4479-4484.

13. Meropol NJ, Weinfurt KP, Burnett CB, Balshem A, Benson AB 3rd, Castel L, Corbett S, Diefenbach M, Gaskin D, Li Y, Manne S, Marshall J, Rowland JH, Slater E, et al. Perceptions of Patients and Physicians Regarding Phase I Cancer Clinical Trials: Implications for Physician-Patient Communication. J Clin Oncol. 2003; 21:2589-2596.

14. Jenkins V, Solis-Trapala I, Langridge C, Catt S, Talbot DC, Fallowfield LJ. What oncologists believe they said and what patients believe they heard: an analysis of Phase I trial discussions. J Clin Oncol. 2011; 29:61-68.

15. Le Tourneau C, Lee JJ, Siu LL. Dose Escalation Methods in Phase I Cancer Clinical Trials. J Natl Cancer Inst. 2009; 101:708-720.

16. Ansher SS, Scharf R. The Cancer Therapy Evaluation Program (CTEP) at the National Cancer Institute: industry collaborations in new agent development. Ann. New York Acad Sci. 2001; 949:333-340.

17. Theradex: Theradex Systems Inc, NCI - CTMS: 2012; http://www.theradex.com/CTMS/Downloads/CTMS CRF Manual_313_2009Mar.pdf(accessed 09/28/2014).

18. Le Tourneau C, Razak AR, Gan HK, Pop S, Diéras V, Tresca P, Paoletti X. Heterogeneity in the definition of dose-limiting toxicity in Phase I cancer clinical trials of molecularly targeted agents: a review of the literature. Eur J Cancer. 2011; 47:1468-1475.

19. Hosmer D, Lemeshow S, : Applied Logistic Regression, 2nd Edition. Wiley Series in Probability and Statistics. (New York, NY: John Wiley and Sons) 2000, P.261.

20. Sima CS, Jarnagin WR, Fong Y, Elkin E, Fischer M, Wuest D, D'Angelica M, DeMatteo RP, Blumgart LH, Gönen M. Predicting the risk of perioperative transfusion for patients undergoing elective hepatectomy. Ann Surg. 2009; 250:914-21. 
21. Ploquin A, Olmos D, Ferte C, Cassier PA, Kramar A, Duhamel A, Penel N. Life-expectancy of patients enrolled in phase 1 clinical trials: A systematic review of published prognostic models. Crit Rev Oncol/Hematol. 2012; 83:242-248

22. Garrido-Laguna I, Janku F, Vaklavas C, Falchook GS, Fu S, Hong DS, Naing A, Tsimberidou AM, Wen S, Kurzrock R. Validation of the Royal Marsden Hospital prognostic score in patients treated in the Phase I clinical trials program at the MD Anderson Cancer Center. Cancer. 2012; 118:1422-1428.

23. Iasonos A, Wilton AS, Riedel ER, Seshan VE, Spriggs DR. A comprehensive comparison of the continual reassessment method to the standard $3+3$ dose escalation scheme in Phase I dose-finding studies. Clin Trials. 2008; 5:465-477. 